\title{
Case workers in family court: A therapeutic jurisprudence analysis
}

\author{
Vicki Lens $^{\text {b,* }}{ }^{\text {, Colleen Cary Katz }}{ }^{\text {b }}$, Kimberly Spencer Suarez ${ }^{\text {a }}$ \\ a Columbia University School of Social Work, United States \\ b C.U.N.Y. at Hunter College, Silberman School of Social Work, United States
}

\section{A R T I C L E I N F O}

\section{Article history:}

Received 8 April 2016

Received in revised form 27 June 2016

Accepted 28 June 2016

Available online 29 June 2016

\section{Keywords:}

Family court

Child maltreatment proceedings

Caseworkers

Judges

Therapeutic jurisprudence

\begin{abstract}
A B S T R A C T
This study explores interactions between judges and caseworkers in child maltreatment cases. We examined the extent to which judges demonstrated therapeutic jurisprudence principles (TJ) in their courtroom interactions in light of past findings linking such practices with positive outcomes. Ninety-four child maltreatment proceedings were observed over a one-year period between 2012 and 2013. We found that while some judges created respectful, empathetic, and supportive environments that included caseworkers, other interactions were more negative. Although caseworkers had the most knowledge of, and experience with families, their participation was limited, and conversations were often directed through the attorneys. Shaming rituals also occurred, with judges criticizing workers for the quality of their work, the slowness of the bureaucracy, and other deficiencies. The findings highlight the importance of applying the principles of $\mathrm{TJ}$ to all court actors, especially in the family court milieu, where courtrooms are populated by a team of professionals who share the common goal of rehabilitating families when appropriate.
\end{abstract}

(c) 2016 Elsevier Ltd. All rights reserved.

\section{Introduction}

Adjudicating child maltreatment cases is a complex- and often contradictory-mix of the legal and the social and psychological. Its scaffolding is the adversarial system, but its tools are those of a social worker. Its professional work group is also a hybrid, populated by both legal professionals, including judges and lawyers, and social service workers, mainly child welfare caseworkers. It requires judges and lawyers to think like social workers, and social workers to think like lawyers. Its conflicting demands, to both adjudicate guilt and "fix" families, result in often challenging and sometimes combative courtroom interactions.

This paper is part of a larger ethnographic study of child maltreatment proceedings in a traditional family court in an urban city. It draws on the theoretical framework of therapeutic jurisprudence (TJ), which provides a model for positive courtroom behaviors. TJ recognizes that legal processes and legal actors have extra-legal effects on litigants' wellbeing. It recognizes that legal interactions are also social interactions, and that how people are treated in court not only matters, but can also affect outcomes. The overall goal of the study is to inform and improve courtroom practices in child maltreatment cases by delineating and illustrating the differences between positive and negative interactions, as defined by TJ.

The tenets of TJ are a natural fit with Family Court, whose explicit mission is to rehabilitate families and where parents' psychological and social wellbeing is the target of change, rather than ancillary to the legal case. While neglect or abuse charges are adjudicated in trial-

\footnotetext{
* Corresponding author.

E-mail addresses: vl2012@columbia.edu, VL531@hunter.cuny.edu (V. Lens).
}

like procedures, most courtroom interactions are more informal and focused on the intimate details of a disrupted domestic life. There are typically wide ranging discussions about the parents' progress and the status of family relationships. As the choreographer of the proceedings, the judge directs these discussions, setting their tone and tenor.

The study's first set of findings focused on the courtroom exchanges between judges and parents, and described the range of judicial styles when interacting with parents. It found that on one end of the spectrum were judges, contrary to the precepts of TJ, who engage little, or not at all with parents, preferring to speak only to the professional court actors. When they did speak to parents they often used shaming rituals, criticizing or lecturing them (Lens, in press). On the other end of the spectrum, and less common, was a more therapeutic approach, with judges weaving participants into courtroom exchanges, engaging them in informational and decision-making dialogues, and praising and supporting them. That some judges, no matter how few, were able to transform non-therapeutic courtrooms into therapeutic ones suggests that $\mathrm{TJ}$ and other problem-solving techniques can be effectively deployed in even the most overburdened and under resourced of traditional family courts (Lens, 2015).

As described below, much of the literature on TJ has focused on the recipients of legal action, respondents or defendants. Missing are studies that focus on other essential actors in the courtroom. This paper examines the interactions between judges and a key player in child maltreatment cases, child welfare caseworkers. Caseworkers are responsible for gathering information, assessing families, and making recommendations. Their written reports inform what the court does, and they are often physically present in the courtroom, providing testimony or information. As the professional tasked with rehabilitating families, 
caseworkers also have an ongoing and active presence in parents' daily lives. Their interactions with judges thus reverberate beyond the courtroom. For example, a judge who models negative behavior, by berating or criticizing a child welfare worker in the presence of a parent, may be encouraging the parent to disrespect or disregard the worker, while more positive interactions can do the opposite.

\subsection{Caseworkers' roles and responsibilities in child maltreatment proceedings}

The work of a child welfare caseworker is one of contradiction and conflict. They are at once partners and adversaries; their allegiance is to the child, whose safety must be protected, but much of their focus is on rehabilitating parents (Beckett, McKeigue \& Taylor, 2006; Butler, Atkinson, Magnatta \& Hood, 1995). They carry a large stick-the threat of removing a child from the home or keeping a child in foster care-while also dispensing the carrots of support and resources to parents. The information they gather during an investigation may help parents, but also may hurt them, and may be used against them. This conflict is embodied in federal law, which requires that reasonable efforts be made to preserve families while at the same time protecting children from harm.

This conflict is even more pronounced when child maltreatment cases are adjudicated in family court. The setting is adversarial, and hence only heightens the conflict between two disciplines, social work and law, whose professional values can collide. While law emphasizes zealous advocacy, adversarial relationships, and formality, social work values empathy, a holistic approach, and more informal helping mechanisms (Van Wormer, 1992). Negotiating these differences in an adversarial setting is difficult, with territorial conflicts over which tasks are legal and which involve social work. Conflicts can arise through all aspects of the proceeding, including when charges should be filed, the framing of allegations, who should testify, and what disposition should be sought (Russel, 1988).

There is ample evidence that caseworkers experience discomfort in family court (Ellet \& Steib, 2005; Beckett, McKeigue \& Taylor, 2006; Butler, Atkinson, Magnatta \& Hood, 1995; Dickens, 2006; Faller, Grabarek, \& Vandervort, 2009; Kisthardt, 2006; Knepper \& Barton, 1997; Russel, 1988; Faller, Grabarek, \& Vandervort, 2009; Van Wormer, 1992; Smith \& Donovan, 2003). Beyond parents, it is caseworkers whose efforts and assessments are most scrutinized. This scrutiny, by often a multitude of higher status lawyers and the judge, may at times be unduly harsh, and disregarding of workers' knowledge and expertise (Dickens, 2006). Child welfare caseworkers are often balancing extremely large caseloads, involving numerous family members in need of crisis intervention, support, and rehabilitation. As one study found, their interests and those of the judge may collide, with judges more focused on securing documentary proof of events and whether mandated services have been completed, and caseworkers with the substance and utility of those services (Smith \& Donovan, 2003). They may become the scapegoat in the courtroom, blamed for not doing enough, or doing it poorly, when complicated and challenging cases go awry (Ellet \& Steib, 2005). As the face of the child welfare bureaucracy, they may serve as an easy and accessible target for judges who are frustrated with what they, and often the public, perceive as its incompetency.

Family courts, though, are not monolithic, and practices can vary from court to court, and among different courtrooms within the same court. Caseworkers can become "bureaucratic allies," part of the professional work group, and judges with limited time and information about cases may rely heavily on workers' assessments and expertise (Knepper \& Barton, 1997). Overall, though, there is considerable evidence that family courts are stressful environments for caseworkers, and a contributing factor to child welfare worker burnout and attrition (Vandervort, Gonzalez, \& Faller, 2008; Flower, McDonald, \& Sumski, 2005). This may especially be the case for women and people of color; as one study of caseworkers found, being older, white and male was associated with higher degrees of comfort in family courts (Faller, Grabarek and Vandervort, 2009).

Adjudication and rehabilitative efforts occur over a course of months, even years, and require repeated and regular court appearances. Caseworkers play a key role, and while much of their work occurs outside the courtroom, these regular court appearances serve as a public display and denouement of their efforts, and the family's progress. Whether they ripen into occasions of support or shame is primarily in the hands of the judge, and the tone and tenor he or she sets. Therapeutic jurisprudence, described next, is one way to insure beneficial courtroom interactions.

\subsection{Therapeutic jurisprudence and family courts}

Therapeutic jurisprudence (TJ) emphasizes the social and psychological impact that law, legal procedures and legal actors (judges and lawyers) have on people and society, and strives for an outcome that enhances people's wellbeing. It encompasses both the micro, or particular rules, laws and interactions, and the macro, or whole bodies of law (Wexler, 1993). The main child welfare statutory scheme-the federal Adoption and Safe Families Act-and the enhanced responsibility it gives to the court to ensure children a "safe, permanent and stable home," is a natural fit with the principles of TJ. As Babb describes, Family Court judges function, in essence, as therapeutic agents, and "strive to protect families and children from present and future harms, to reduce emotional turmoil, to promote family harmony or preservation, and to provide individualized and efficient, effective justice"(Babb, 1996-97, p. 800).

Thus while Family Court judges preside in an adversarial setting, much of the focus is on motivating behavioral change, a task especially suited to TJ. TJ provides a helpful set of practices, drawn from the psychological and behavioral sciences, to influence behavior. Based on the principles of voice, validation, respect, and self-determination, it envisions a more active role for participants (King, 2009). In contrast to more formal adversarial proceedings, where attorneys do much of the talking, participants are encouraged to actively participate in court dialogues, including shaping solutions (King, 2009). Support and positive inducements are preferred over threats and coercion. Sanctions are available, but used sparingly, as an educational and reflective tool rather than a punitive one. More common are rewards for good behavior rather than sanctions for bad behavior (Fay-Ramirez, 2015).

TJ also values collaboration over conflict, and teamwork over winning legal arguments (Fay-Ramirez, 2015; Castellano, 2011; Winick, 2002-2003). Judges, thus, do more than preside over proceedings, maintaining order and issuing decisions. They also fulfill an essential leadership role, providing guidance, and even inspiration, to all of the various court actors working toward a common, rather than an adversarial, goal (King, 2009). As such, they are expected to model positive behavior while encouraging it in others. While traditional judges strike a passive, neutral pose, a therapeutic judge is more active and engaged, displaying compassion and empathy (Nolan, 2002).

$\mathrm{TJ}$ is used most often in more specialized problem-solving courts, where its effectiveness has been demonstrated. Several studies have shown that Family Treatment Courts, which incorporate therapeutic jurisprudence techniques for families with substance abuse problems involved in child maltreatment proceedings, resulted in shorter foster care placements and a greater likelihood that children would be returned to their parents as compared to children in traditional courts (Bruns, Pullman, Weathers, Wirschem \& Murphy, 2012; Green, Furrer, Worcel, Burrus \& Finigan, 2007; Worcel, Furrer, Green, Burrus \& Finigan, 2008; c.f. Picard-Fritsche, Bryan, Kralstein \& Farley, 2011). Several studies in the related arena of drug courts, which like family court proceedings require behavioral changes to achieve better outcomes, and where a TJ approach is more likely to be used, have found positive effects including better adherence to treatment plans and lower rates 
of recidivism (Satel, 1998; Senjo \& Leip, 2001; Aos, Miller and Drake 2006; Latimer, Morton-Bourgon and Chretien, 2006; Downey and Roman, 2010; Rossman et al., 2011). While other variables may be at work, particularly in specially designed courts that offer enhanced access to resources and other benefits, these studies suggest that TJ techniques make a difference.

To be effective, such techniques need to encompass all courtroom participants. Courtrooms are their own eco-systems; how the judge acts and behaves toward all actors sets the tone, and reverberates around the room. Courts, like any organization, are also comprised of work groups guided by rules and informal norms (Knepper and Barton, 1997). This is especially the case in the family court milieu, where courtrooms are populated by a group of professionals who, while labeled as adversaries, have the common goal of rehabilitating families when possible. The work groups that crowd the courtroom of a typical child maltreatment case include, in addition to the judge, multiple attorneys (for the parent(s), the child(ren), and the agency) and at least one, and sometimes more, child welfare or other social service workers.

While part of the work group, caseworkers stand out. Unlike the legal professionals, they serve as witnesses. In urban areas, as in this study, they are likely to share the same ethnicity-African-American-as the parents (National Child Welfare Workforce Institute; See also Boyd, 2014). They also have ongoing relationships with parents out of court, and have more knowledge of the case than most other court actors. Thus, while higher status attorneys nearly always outnumber caseworkers, the latter are pivotal players. How they are treated and the extent to which they are involved in court can influence the course of the case.

Using ethnographic methods, this study dissects the nature of interactions between judges and caseworkers. It found that some judges created respectful, empathetic, and supportive environments that included caseworkers and, as found in the first set of findings, parents as well. Other interactions with caseworkers, however, replicated in form and substance the types of negative encounters that often took place between judges and parents. Although workers had the most knowledge of, and experience with families, their participation was limited, and conversations were often directed through the attorneys. Similar to how parents were treated, shaming rituals occurred, with judges criticizing workers for the quality of their work, the slowness of the bureaucracy, and other deficiencies. The failure to create a more collaborative environment also exacerbated the already lowly status of caseworkers among a work group of professionals largely composed of attorneys.

\section{Methodology}

This study draws on data from an urban Family Court located in a state in the northeastern United States. The data are the result of a focused ethnography, a type of sociological ethnography that examines specific and well-defined interactions, acts, or social situations in the field rather than an entire system or culture (Knoblauch, 2005). Focused ethnography is characterized by relatively short-term field visits and intensive data collection to observe specific structured events or activities. It is especially suited to the observation of courtroom interactions, which are a form of structured social interaction bounded in space and time, with a well-defined beginning and end and cast of characters.

Ninety-four child welfare and abuse proceedings were observed over a one-year period between 2012 and 2013, with forty-six observations conducted by the first author, and forty-eight conducted by a research assistant. Caseworkers attended 73 of these hearings, sometimes in multiples, for a total of 98 caseworkers observed. All but 3 of the caseworkers were African-American or Latino. The respondents/parents observed were, with one exception, also African-American or Latino.

During the time period of the observations, nine judges were assigned to the Family Court. Eight of the nine judges were observed multiple times over multiple observation days, and with one exception, were observed both by the research assistant and the first author at different times. The use of two researchers observing the same site allowed observations to be crosschecked, thus increasing the trustworthiness of the data (Erlandson et al., 1993). The research was approved by an Institutional Review Board.

Judges were assigned cases randomly, and cases were not distinguished by level of severity. Thus each judge's caseload was similar to every other judge's. Seven judges were female, of which one was African American, and the rest Caucasian. The one male judge observed was Latino. The length of services on the bench ranged from one year to sixteen years, with the average length of service seven years.

Initially, all types of proceedings involving child abuse and neglect were observed, including initial intakes, emergency removal hearings, fact-finding hearings where charges of abuse or neglect are adjudicated, and dispositional or permanency planning hearings, where decisions are made as to where the child will live. Initial observations revealed a distinction between formal court processes, such as the taking of testimony, and less formal ones, where after a charge of maltreatment was adjudicated or admitted court actors discussed the family's progress and service needs. This study focused on the latter because they were more likely to involve rehabilitative efforts than adjudication.

During the hearings a detailed log was maintained, recording both what was said (as much as was able to be recorded) and other observations. These other observations include physical descriptions of the parties and the environment of the room; obvious states of emotions (e.g., anger, crying, laughter); the parties' demeanor, tone, and style (e.g., authoritarian, conciliatory, antagonistic); and affective quality of personal interactions (e.g., friendly, hostile, apathetic). Routine and standardized data for each hearing observation were also recorded. These include the parties present, the issue that prompted the hearing, and the length of the hearing. Field jottings and observations were transferred into full field notes immediately after actual observations. In-process memos were used to "identify and develop analytic themes" (Emerson, Fretz \& Shaw, 1995, p. 100).

The data were analyzed using thematic analysis, which has been defined as a "method for identifying, analyzing and reporting patterns (themes) within data" (Braun \& Clark, 2006, p. 79; Guest, MacQueen \& Namey, 2012). Line-by-line coding was conducted first. As an example, variations in participation were noticed, specifically that in some proceedings judges did not directly engage in conversation with caseworkers, while others did. The code "attorney middleman" was used when the judge spoke to the caseworker through the attorney and vice versa. The code "querying caseworker" was used for exchanges where the judge was information gathering, asking questions or otherwise gathering facts about the case from the caseworker. These and other codes were then used to develop the properties and dimensions of the themes "participation" and "non-participation."

Similarly, line by line coding was used to develop the themes of "collaboration" or "conflict." As an example, the code "blaming" was used when the judge spoke to the caseworker in a manner that either directly lays blame on him/her or implies that the caseworker is to blame for some problem or failing related to the present case. The code "supportive" was used when the judge praised, complimented or made encouraging comments to a caseworker. Nonverbal behaviors, including facial expression, tone, and demeanors were also captured with such codes as "furrowed brow," a facial expression that one typically associates with anger or consternation, and "angry voice" which is characterized by a sharper, louder and more staccato speech (See Maroney, 2012).

Data sessions were also conducted between the first author and a research assistant, who, as noted above, also conducted observations. The purpose of these meetings was to compare our analyses and interpretations of the data, and to reach consensus on the defining themes and their properties and dimensions. 


\section{Findings}

\subsection{Participation or silence?}

As noted above, of all the professional court actors caseworkers possess the most knowledge about a family. They visit the family outside of court, gather information about the family, and monitor their compliance with court ordered services. Whether testifying in court, or appearing during the more informal conferences, they are key players as a child maltreatment case unfolds. Their importance though is seldom commensurate with their status. In the hierarchy of the courtroom they occupy a middle rung; they have less authority and status than judges and attorneys but more than parents. While caseworkers are part of the "work group" that comprises a child maltreatment case, they also stand apart, subject to the same oath as parents and other witnesses, and the same protective presence of an attorney. The latter especially sets the stage for their silence, because it is a rule and custom of the adversarial process to have attorneys speak for their clients.

While these protections are integral to the adversarial system, as described earlier many courtroom interactions are focused on rehabilitating parents and repairing family relationships rather than adjudicating guilt. These encounters consist of wide ranging discussions about the parents' progress and the status of family relationships. As described next, some judges engaged caseworkers and wove them into the fabric of the proceedings. In contrast, in other instances caseworkers remained mostly silent during the proceeding, communicating with the judge through their attorney, if at all.

\subsubsection{Engaged caseworkers}

As described above, a bedrock principle of $\mathrm{TJ}$ is the value of participation, and the emphasis on teamwork to solve problems. The most visible and public manifestations of this are the periodic hearings where a family's progress is monitored, and all of the various court actors, including caseworkers, come together. Some judges created a participatory, inclusive atmosphere, often turning to the caseworkers to clarify and elaborate on the family's status or progress. In such instances, judges relaxed the rules of the adversarial process, speaking directly to caseworkers rather than though the attorneys, drawing them into the dialogue between the parties. They consulted directly with caseworkers on a range of matters related to their knowledge and expertise, such as the state of a child's heath, the living conditions in the home, or whether a parent had attended mandated mental health services. Caseworkers filled in missing information, or provided new information, at times interjecting without being directly asked a question by the judge. In an illustrative example, as new information emerged that a child in foster care may be neglected, the caseworker fully participated in the ensuing dialogue, sometimes without prompting by the judge

The judge asked to be updated on the family's progress. The attorney for one of the children described a Facebook message posted by the child about waiting outside, hungry and in the cold after returning to the foster home from school. The judge asked if the child welfare agency knew about it, and how it was being handled. The caseworker responded that the agency was not aware of this, that they would take note and would engage in closer monitoring.The judge then established eye contact with the caseworker and asked directly about the child's living conditions, speaking calmly and with a facial expression that conveyed concern and keen attention. The caseworker described the need to make more particular arrangements with the foster mother and for closer monitoring. After a discussion between the caseworker and the child's attorney about the child lacking a key to get into the foster home after school, the judge asked if it "has happened multiple times?" The child's attorney explained it was a regular occurrence according to the reports. The judge in response asked "And she's coming home in the dark, not able [to get in]?" Another caseworker, seated in back stood up, interjected: "This is the first we're hearing about this... will follow up...can certainly remove her if appropriate."

In another example, a caseworker similarly responded to unfolding events in real time, rather than quietly or passively waiting for the attorney to speak on her behalf.

The judge asked how the mother was doing in her "program." An attorney noted the mother's imminent graduation from the program and that she wanted the child to attend. A caseworker, seated against the back wall of the courtroom (and not at counsels table) interjected that the agency would be closed that day, so no one would be available to bring the child, but that arrangements might be made "if [the mother] can identify someone to accompany [the child]." The child's attorney requested that that person be identified as soon as possible. The caseworker responded by noting they "were not notified of this," and that graduation is "not on a working day", but that "It will be either that a (child welfare agency) approved person will bring the child to the agency or Ms. _ (the foster mother) will bring [the child]."

As these excerpts illustrate, interactions were more free-flowing and fluid than the more structured dialogues characteristic of the adversarial process. The judges allowed, and even encouraged, the caseworkers to speak out of turn and on their behalf, thus creating a more participatory environment. The caseworker was positioned as an active and vital actor, on matters big and small, from a child's safety to the logistics of arranging contacts between parent and child.

\subsubsection{Silent caseworkers}

Other times judges interacted little with caseworkers, addressing them not at all or indirectly through the attorney for the child welfare agency. During these times, judges chose to adhere more strictly to the rules of the adversarial process, and preferred speaking primarily to the attorneys, who served as "middlemen" to other court actors, including caseworkers. Judges would ask attorneys questions within the province and knowledge of caseworkers, resulting in a cumbersome communication chain, with attorneys serving as an information conduit between the judge and caseworker

In an illustrative example, the judge and attorney engaged in an exchange over a missing birth certificate required to complete a permanency plan, as the caseworker sits silently:

The judge asked the attorney for the child welfare agency whether the caseworker had the child's birth certificate. The attorney responded "My client didn't know she would need it." The judge said: "That's not what I'm asking. Does she have a copy of the birth certificate?" The attorney explained that the caseworker had the birth certificate "but unfortunately does not have it with her in her file today." The judge responded: "So she will provide the child's birth certificate to the court by 5pm today." At the end of the exchange the caseworker rolled her eyes, leaned back in her chair and groaned quietly.

As this exchange illustrates, the caseworker was relegated to a silent role in the courtroom. Referred to in the third person as "she", she was spoken about, and not to. Orders from the judge were communicated via an attorney, and again in the third person, without any input from the caseworker or inquiry as to whether the $5 \mathrm{pm}$ deadline was reasonable given her other responsibilities. Her body language, accompanied by a soft groan, was her only visible means of communication.

In addition to their physical presence, often mandated, caseworkers also contribute to court proceedings through their written reports. Caseworkers' reports are a staple of child maltreatment proceedings, and are the primary conduit for information about a family. They contain a trove of facts, gathered through a caseworker's visits and other sources. They also include the caseworker's assessment based on 
those facts. They are one of the chief sources judge use to made decisions, and many proceedings begin with the judge reading, either silently or sometimes out loud, from the report.

Judges, though, did not always solicit comments or clarifications from caseworkers about their reports, even as they referenced them, letting a caseworker's written words, or an attorney's summation of them, suffice. An illustrative example involved a proceeding where it was alleged that the mother violated an Order of Protection by allowing the father to interact with the child. A request was made to remove the child and return her to foster care. A dispute arose over the foster mother and child's relationship: the mother, through her attorney, expressed concerns over the relationship while the opposing counsel described it more favorably, referencing statements in the caseworker's report to support her characterization. The judge did not call upon the caseworker (the author of the report, who was present) to expand upon this perspective, but, instead, looked to the attorney to do so.

Another example involved a permanency planning hearing for children who were being placed in kinship care with their grandmother, and where the judge referenced a caseworker's report about the living conditions, asking if there was enough space for all of the children. The attorney noted that the worker was meeting with the children to smooth their transition into the home and to negotiate the sharing of space, which was limited and was a source of conflict. The judge did not solicit any additional information from the caseworker about the children's living conditions, the space available, and the nature and extent of the conflict before making her decision to approve the permanency plan.

As these examples illustrate, although caseworkers know and see family members more frequently than lawyers or judges, their contributions were not always solicited at opportune times despite their value and relevancy. Such moments suggested missed opportunities for expanding upon the written evidence submitted by the caseworker, and to hear in the caseworkers' own words what they knew and thought about a family's situation.

To be sure, judges may have simply judged the information contained in reports sufficient, without further elaboration, for rendering a decision. Relying only on the caseworker's written words, and those of the attorney, rather than engaging the worker in an extended dialogue, are also time saving devices in very busy courtrooms. As studies of public welfare bureaucracies have shown, workers routinely rely on shortcuts to allow them to process large numbers of cases (Lipsky, 1980, Brodkin, 1997; Maynard-Moody and Musheno, 2003). Such shortcuts can also involve weighty decisions about a person's deservingness and moral character, as workers quickly "put a fix on people" asking for their help (Maynard-Moody and Musheno, 2003, 21). Judges are no less insulated from this phenomenon, and particularly in child maltreatment cases must quickly synthesize a brew of facts with judgments about character. Thus judges become skilled in excerpting relevant information from reports and rendering rapid psychosocial and legal judgments.

Occasionally, though, the sidelining of caseworkers appeared less a function of time and expediency than role confusion when judges are routinely called upon to make decisions that are primarily social or psychological in nature. Consequently, judges sometimes substituted their own opinions for those of the caseworker. An illustrative example involved a judge who disagreed with a service plan for a father, deciding to switch him from a domestic violence program to a batterer program, although conceding that she didn't "know what batterers' programs consist of" and while also opining that he didn't need "anger management." In other instances, judges ordered psychiatric or other mental health services without appearing to consult with caseworkers.

In sum, whether a judge chooses to directly engage or not with caseworkers may be a function of the rules of the adversarial system, and/or a judge's particular judicial style, with some judges choosing to more strictly follow those rules. It may also vary from case to case, based on such factors as time constraints, the completeness of written reports, and the value of any additional information, as perceived by the judge. Overall and over time, engaging little or not at all with caseworkers consigns them to a less visible role within the courtroom. It suggests that despite the caseworker's greater knowledge and expertise they are of secondary value in the courtroom.

\subsection{Collaboration or conflict?}

Child maltreatment cases are a blend of the collaborative and the adversarial. Unlike most other courts, Family Court has an explicit dual mission, first to adjudicate guilt, and then to rehabilitate. Judges thus rely on caseworkers both for evidence of guilt, and evidence of rehabilitation. In court, caseworkers are the parent's legal adversary; the agency they work for is the party that initiated the charge of child maltreatment, and who must prove that charge in court. How well rehabilitation efforts proceed also depends, in part, on a caseworker's actions. They are the crucial link for facilitating court orders, and making sure that the federal mandate that "reasonable efforts" be made to keep a family together is satisfied where possible. Caseworkers must also routinely record what they do so that their efforts can be assessed and the court informed of the family's progress. Consequently, their words and their actions are regularly scrutinized by the court.

Caseworkers are also institutional actors that represent the governmental agency they serve, the child protection agency. Such agencies have long been criticized for inefficiency and ineptness (See for e.g. Bernstein, 2002). As frontline workers delivering agency services and reporting to the court, caseworkers' actions provide a readily available and highly visible measure of the agency's performance. They can become the fall guy for what may be systemic agency failures. Alternatively, though, they can be viewed as allies in the quest for a family's rehabilitation, despite agency deficiencies, or even individual caseworker mistakes.

TJ emphasizes praise over condemnation, in order to promote selfefficacy, and out for respect for individuals (King, 2009). During some proceedings, some judges showed a greater capacity than others for positively acknowledging caseworkers. As previously discussed, they integrated caseworkers into courtroom discussions, thus elevating their status and importance. They also tended to "cut slack" when a caseworker's records, or actions, fell short, thus suggesting they were cognizant of the demands on the agency and the caseworkers. They resisted publically blaming or chastising the caseworker in open court, and conveyed respect by speaking calmly to caseworkers and maintaining eye contact.

An illustrative example involved a case where the agency had failed to arrange for needed services within the required time limit for permanency planning. Rather than chastise the caseworker, the judge first examined the file for the possible reason, noting "I can see there was another caseworker, so I can see how that may explain the insufficient efforts.". The caseworker then explained that she was the supervisor, and that some of the workers were shuffled because a caseworker left the agency. In a calm, patient, but firm tone, with no hint of harshness the judge noted that "It's been more than 2 months...something should have been done", and suggested that the agency's lawyer be used to "get a bit of muscle behind this.". She concluded by telling the caseworker "hopefully you can be more effective [than the previous caseworkers] in getting things done. Because it's very important that the child receive these services." In short, she looked forward, rather than backward, and did not use the misstep to criticize the worker or the agency.

Some judges also strove to highlight the good work of caseworkers, and publicly applaud them for their efforts. In one such example, after a caseworker updated the court on the family's progress, the attorney for the children interjected "I just want to express ... I'm very pleased with [how the case has proceeded]." The judge built on this comment, telling everyone "You've all worked very diligently ... attorneys, caseworkers." By including the caseworker in her praise, alongside the attorneys, she elevated them to a more equal and important role. 
Other times judges treated caseworkers more critically and punitively, especially when confronted with agency slip-ups. In some instances, judges engaged in antagonistic dialogues with caseworkers, speaking in condescending and paternalistic tones while reprimanding and criticizing them. They interrupted or cut-off caseworkers' responses to their questions, conveying impatience and disdain for their answers, and sometimes spoke in loud tones, slowly articulating their words as though caseworkers could not understand them.

Caseworkers were admonished both for their own mistakes and the perceived failings of the child protection agency overall. An example of the former involved a caseworker whose report was contradicted by several other witnesses, with the judge harshly criticizing the caseworker in open court:

Speaking firmly in a raised voice and confrontational and harsh tones to a caseworker sitting in the back of the courtroom the judge said "Do you want to stand, ma'am? Ma'am, you were aware of the information revealed today regarding $\mathrm{Mr}$.__'s drug testing? And that they can't monitor him because he doesn't attend regularly?" The judge pointed out direct contradictions between what various individuals said in court, and the caseworker's report. The caseworker admitted her "oversight." The judge cut her off and turned her attention to the attorney for the child protection agency to demand that the caseworker's supervisor monitor the case and come to court, stating that "The court cannot rely on this caseworker's reports."

In this example the judge showed disregard for the caseworker in several ways. First, the judge refererred to her as "Ma'am" rather than her formal name, a sign of disrespect. Second, in contrast to the preceding example, she did not seek to understand the discrepancies, or give the caseworker an opportunity to explain, and further made the global assumption that all of the caseworker's reports are unreliable. Finally, by demanding that the caseworker's supervisor monitor the case and come to court, she, in effect, publicly proclaimed the caseworker as inept.

Judges sometimes made little distinction between the caseworkers standing before them and the agency, treating the former as responsible for any and all agency mistakes that may have occurred, regardless of an individual caseworker's culpability. An illustrative example involved a child who had been injured while in foster care. After reading the case reports, the judge faulted the agency for not responding quickly and appropriately, directing her ire at the caseworker present in the courtroom. Speaking slowly, loudly and deliberately to the caseworker, while furrowing her brow in a frown, the judge complained that there was insufficient information about the injuries, which were not treated urgently enough. The caseworker explained that the reports were old, and that agency changes had since taken place. The judge cut her off, saying "So next time you'll hand in a report that's accurate", thus suggesting that despite this explanation, the fault still lay with the caseworker, and should be corrected by her.

In another example, upset that the agency had not held a crucial conference about what services the family needed, but had only "explored" the options, the judge told the caseworker in an impatient and irritated voice, “...'explore' means you are doing nothing... I don't make my rules based on your conferences. If I waited for [the agency] to do conferences the cases will take years. I'll give you a week and a half for the conference." As this exchange illustrates, the judge's general ire and irritation with the agency was visited upon the worker.

In sum, judges rely on caseworkers to play a critical role in the courtroom. Cases cannot proceed without the reports and information they provide, and rehabilitation efforts are more likely to fail if the caseworker does not link parents with needed services and monitor their progress. Caseworkers' roles and responsibilities in child maltreatment cases, coupled with often negative perceptions of child protection agencies, makes them a potential target for blame and criticism, rightly or wrongly, when cases go awry. At times, judges chose an antagonistic path, highlighting caseworker and agency error, and conveying anger and disapproval in open court, and often in the presence of parents. Other times, judges took a gentler route, avoiding harshly criticizing caseworkers even when mistakes were made, and treating them as collaborators rather than impediments on the road to a family's rehabilitation.

\section{Discussion}

The principles of TJ which emphasizes participatory and respectful interactions, fit well in the milieu of Family Court, where judges and caseworkers have the same goal, to improve a family's functioning, where possible. While courtroom interactions are often brief, they loom large, setting a case's path, including caseworkers' specific tasks and responsibilities. Judges, in essence, also function as leaders, and, as studies of leadership styles have shown, transformative and inspirational leadership can improve a worker's sense of self-efficacy, while fear and negative thoughts can impair it (Bandura, 1997). Treating caseworkers disrespectfully, or as incompetent, can thus have a ripple effect, impairing how they do their job. The better choice is for the judges to model behavior that invites collaboration and respect.

Similarly, exchanges within court may also set the tone for the caseworker/parent relationship outside of court, and their willingness to comply with court orders. As previous research has found, people are more likely to respect governmental authorities and comply with court orders if they feel they were treated fairly in their interactions with them (Tyler, 2006; Eckberg and Podkopacz, 2004; Paternoster, Brame, Bachman and Sherman, 1997). Negative courtroom interactions, where caseworkers are treated disrespectfully and as less than competent, can undermine the caseworkers' authority and give parents justification to question or challenge the fairness of their requests. Positive courtroom interactions, where caseworkers are treated as valued and competent, can enhance the parent and caseworker's relationship by providing parents with a model of cooperative action toward a shared goal.

Family Court, though, is an arena under constant strain. The dual mandate to protect children and fix families places pressure on judges and caseworkers alike, with both working in institutional environments that are short on time, resources and supports. A caseworker's performance and a judge's decisions are also continually subject to public scrutiny in the very open space of a courtroom. This scrutiny is often harsh, with caseworkers in particular laboring under popular and often pernicious perceptions of child welfare workers as inept. While much of the hard work of rehabilitating families occurs outside the courtroom, the success and failure of those efforts, including the wisdom of a judge's decision or the efficacy of a caseworker's actions, are gauged in the courtroom. Consequently, conflicts and tensions that in other work environments are managed behind the scenes become grist for public discussion and disapproval. This makes caseworkers particularly vulnerable and may explain some of their reported discomfort in the courtroom.

TJ provides a helpful guide to smoothing such exchanges. However, as the findings indicate, judges differed in how much, if at all, they incorporated these techniques in their exchanges with caseworkers. While some judges encouraged collaboration, others invited conflict by chastising caseworkers. Similarly, while some judges were very inclusive of caseworkers, others were less so. They did not routinely invite them to expand upon their assessments and communicated mostly through the agency's attorney, rather than directly with them.

To be sure, this route of communication is supported by the rules of the adversarial process, and some judges may have been unwilling to bend these rules. Such judges may feel more comfortable directing the dialogue through the attorneys. Notably, though, other judges were willing, and hewed less to the strict rules of the adversarial process and more to the principles of TJ. They spoke directly to caseworkers, soliciting their opinions and insights. As noted earlier, such an approach has proven effective in other specialized problem solving courts, 
including mental health and drug courts, and Family Treatment Courts. Especially in regards to caseworkers, who are not the target of child maltreatment proceedings, and hence arguably less in need of the protection adversarial rules provide, a more collaborative, inclusive, respectful and participatory approach would better help the Family Court reach its goal of rehabilitating families.

\section{Policy and practice implications}

The findings suggest several implications for the selection, training and monitoring of judges. While selection of judges vary from jurisdiction to jurisdiction (some are elected, others appointed), judicial competency, especially in the context of Family Court, should emphasize judicial temperament and style, and the ability to function as an inclusive and inspirational leader of a diverse group of court actors. Training that emphasizes these skills should be implemented on an ongoing basis. Judicial performance evaluations, where judges are observed and feedback provided, could insure such skills are implemented and maintained. One such program that could serve as a model is the Utah Courtroom Observation Program, which includes courtroom observations and judicial performance surveys based on such criteria as respectful behavior, neutrality and voice (Woolf and Jennifer Yim, 2011). These data are then used to inform decisions on judicial retention and to train judges. In a similar vein, to improve their performance in court, caseworkers should receive enhanced training in courtroom procedures and expectations and effective methods of communication.

Mechanisms for diffusing tensions in the courtroom between judges and caseworkers should also be explored. One approach is to structure opportunities for judges, caseworkers and supervisors to interact outside of the courtroom for the purpose of making (non-case) specific suggestions on how to collaborate more effectively. Mechanisms could also be incorporated that invite both judges and caseworkers to provide feedback to agency supervisors and court administrators on systemic problems. On an individual level, case specific conflicts involving caseworkers could be addressed in sidebars between the attorneys or the judge's chambers, rather than an open courtroom.

\section{Limitations and future research}

One limitation of this study is that it is limited to a snap shot in time and does not capture any prior interactions between the parties, which may affect present interactions. As an observational study, it also does not include such unobservable factors as caseworkers' level of preparation, background and experience. It is thus limited to interactions that are directly observable in a courtroom, the focus of the study.

Another limitation of this study is that it is limited to observations conducted in a single Family Court, located in an urban area, and which may be dissimilar to other Family Courts on various dimensions, including the severity and number of cases and the characteristics of respondents and caseworkers. An additional limitation is that the influence of gender or ethnicity on judge/caseworker interactions could not be analyzed because there was little variation within the groups. Of the eight judges observed, only one was a male, (who was also the only Latino) and only one was African-American. Similarly, of the 98 caseworkers observed, only 13 were identified as male, and they often appeared alongside female caseworkers. Only 3 caseworkers were identified as white, with the rest either Latino or African-American. This lack of with-in group heterogeneity meant comparisons could not be made based on gender or ethnicity.

Future research should explore, through in-depth qualitative interviews, how judges and caseworkers perceive and experience each other. This would shed additional light on factors that may influence judge/caseworker interactions. Studies involving a more demographically diverse Family Court, and in non-urban locations, would permit a more thorough exploration of the dynamics of ethnicity, gender and place.

\section{References}

Aos, S., Miller, M., \& Drake, E. (2006). Evidence based public policy options to reduce future prison construction, criminal justice costs and crime rates. Federal Sentencing Review, 19(4), 275-290.

Babb, B. A. (1996-97). An interdisciplinary approach to family law jurisprudence: Application of an ecological and therapeutic perspective. Indiana Law Journal, $72,775-808$.

Bandura, A. (1997). Self-efficacy. The exercise of control. New York: Macmillan/Worth Publishers.

Beckett, C., McKeigue, B., \& Taylor, H. (2006). Coming to conclusions: Social workers' perceptions of the decision-making process in care proceedings. Child \& Family Social Work, 12(1), 54-63.

Bernstein, N. (2002). The lost children of Wilder. New York: Vintage.

Boyd, R. (2014). African American disproportionality and disparity in child welfare: Toward a comprehensive conceptual framework. Children and Youth Services Review, $37,15-27$.

Braun, V., \& Clarke, V. (2006). Using thematic analysis in psychology. Qualitative Research in Psychology, 3(1), 77-101.

Brodkin, E. (1997). Inside the welfare contract: Discretion and accountability in state welfare administration. The Social Service Review, 71, 1-33.

Bruns, E. J., Pullman, M. D., Weathers, E. S., Wirschem, M. L., \& Murphy, J. K. (2012). Effects of a multidisciplinary family treatment drug court on child and family outcomes: Results of a quasi-experimental study. Child Maltreatment, 17(3), 218-230.

Butler, S., Atkinson, L., Magnatta, M., \& Hood, E. (1995). Child maltreatment: The collaboration of child welfare, mental health, and judicial systems. Child Abuse \& Neglect, 19(3), 355-362.

Castellano, U. (2011). Courting compliance: Case managers as "double agents" in the mental health court. Law \& Social Inquiry, 36, 484-511.

Dickens, J. (2006). Care, control and change in child care proceedings: Dilemmas for social workers, managers and lawyers. Child and Family Social Work, 11, 23-32.

Downey, M. P., \& Roman, J. K. (2010). A Bayesian meta-analysis of drug court cost-effectiveness. (Retrieved from Washington D.C.).

Eckberg, D. A., \& Podkopacz, M. R. (2004, May). Family court fairness study. Fourth Judicial District of the State of Minnesota.

Ellet, A. J., \& Steib, S. D. (2005). Child welfare and the courts: A statewide study with implications for professional development, practice, and change. Research on Social Work Practice, 15(5), 339-352.

Emerson, R. M., Fretz, R. I., \& Shaw, L. L. (1995). Writing ethnographic fieldnotes. Chicago: Chicago University Press.

Erlandson, D. A., Harris, E. L., Skipper, B. L., \& Allen, S. D. (1993). Doing naturalistic inquiry: A guide to methods. Thousand Oaks, California: Sage.

Faller, K. C., Grabarek, M., \& Vandervort, F. (2009). Child welfare workers go to court: The impact of race, gender, and education on the comfort with legal issues. Children and Youth Services Review, 31, 972-977.

Fay-Ramirez, S. (2015). Therapeutic jurisprudence in practice: Changes in family treatment court norms over time. Law \& Social Inquiry, 40(1), 205-236.

Flower, C., McDonald, J., \& Sumski, M. (2005). Review of turnover in Milwaukee County Private Agency Child Welfare Ongoing Case Management Staff. (Retrieved January 3, 2013 from) http://www.jessmcdonald.a25hourdaysites.com/f/Wisconsin_Report.pdf

Green, B. L., Furrer, C. Worcel, S., Burrus, S., \& Finigan, M. W. (2007). How effective are family treatment drug courts? Outcomes from a four-site national study. Child Maltreatment, 12(1), 43-59.

Guest, G., MacQueen, K. M., \& Namey, E. E. (2012). Applied thematic analysis. Thousand Oaks, CA: Sage.

King, M. (2009). Solution-focused judging bench book. Melbourne, Australia: Australasian Institute of Judicial Administration Inc.

Kisthardt, M. K. (2006). Working in the best interest of children: Facilitating the collaboration of lawyers and social workers in abuse and neglect cases. Rutgers Law Record, $30(1)$

Knepper, P. E., \& Barton, S. M. (1997). The effect of courtroom dynamics on child maltreatment proceedings. Social Service Review, 71(2), 288-308.

Knoblauch, H. (2005). Focused ethnography. Forum: Qualitative Research, 6(Art. 44).

Latimer, J., Morton-Bourgon, K., \& Chretien, J. -A. (2006). A meta-analytical examination of drug treatment courts: Do they reduce recidivism. (Retrieved from Ottawa, Ontario).

Lens, Vicki (2015). Against the grain: Therapeutic judging in a traditional Family Court. Law E' Social Inquiry. http://dx.doi.org/10.1111/lsi.12153.

Lens, Vicki (2016). Engaging parents in Family Court: Lessons from an observational study of child protection cases. Journal of Social Work (in press)

Lipsky, M. (1980). Street-level bureaucracy: Dilemmas of the individual in public service. New York Russell Sage Foundation.

Maroney, T. (2012). Angry judges. Vanderbilt Law Review, 65(5), 1207-1286.

Maynard-Moody, S., \& Musheno, M. (2003). Cops, teachers, counselors: Stories from the front lines of public service. Ann Arbor: University of Michigan Press.

Nolan, James L. (2002). Therapeutic Adjudication. Society, 39(2), 29-38.

Paternoster, R., Brame, R., Bachman, R., \& Sherman, L. W. (1997). Do fair procedures matter? The effect of procedural justice on spouse assault. Law E Society Review, 31(1), 163-204.

Picard-Fritsche, S., Bryan, J., Kralstein, D., \& Farley, E. (2011). The Bronx family treatment court 2005-2010: Impact on family court outcomes and participant experiences and perceptions. New York: Center for Court Innovation.

Rossman, S. B., Rempel, M., Roman, J. K., Zweig, J. M., Lindquist, C. H., Green, M., \& Farole, D. J. (2011). What have we learned from the multi-site adult drug court evaluation? Implications for policy, practice, and future research. (Retrieved from Washington D.C.).

Russel, R. (1988). Role perceptions of attorneys and caseworkers in child abuse cases in juvenile court. Child Welfare, 67(3), 205-216. 
Satel, S. (1998). Observational study of courtroom dynamics in selected drug courts. National Drug Court Institute Review, 1(1), 43-72.

Senjo, S., \& Leip, L. (2001). Testing therapeutic jurisprudence theory: An empirical assessment of the drug court process. Western Criminology Review, 3(1), 1-21.

Smith, B., \& Donovan, S. (2003). Child welfare practice in organizational and institutional context. Social Service Review, 77(4), 541-563.

Tyler, T. (2006). Why people obey the law. Princeton, New Jersey: Princeton University Press.

Vandervort, F. E., Pott Gonzalez, R., \& Coulborn Faller, K. (2008). Legal ethics and high child welfare worker turnover: An unexplored connection. Children and Youth Services Review, 30(5), 546-563.

Van Wormer, K. (1992). No wonder social workers feel uncomfortable in court. Child and Adolescent Social Work Journal, 9(2), 117-129.
Wexler, D. B. (1993). Therapeutic jurisprudence and changing concepts of legal scholarship. Behavioral Sciences \& the Law, 11, 17-29.

Winick, B. J. (2002-2003). Therapeutic jurisprudence and problem solving courts. Fordham Urban Law Journal, 30, 1055-1090.

Woolf, N., \& Jennifer Yim, J. (2011). The courtroom-observation program of the Utah judicial performance evaluation commission. Court Review, 47(1-2), 84-91.

Worcel, S. D., Furrer, C. J., Green, B. L., Burrus, S. W., \& Finigan, M. (2008). Effects of family treatmnt drug courts on substance abuse and child welfare outcomes. Child Abuse Review, 17(6), 427-443. 